\title{
An Unusual Case of Submucosal Invasion of Esophageal Squamous Cell Carcinoma Mistaken as Primary Achalasia
}

\author{
Jung Ho Park, MD*, Dong II Park, MD, Hong Joo Kim, MD, Yong Kyun Cho, MD, Chong II Sohn, MD, Woo Kyu Jeon, MD, \\ and Byung Ik Kim, MD
}

Department of Medicine, Kangbuk Samsung Hospital, Sungkyunkwan University School of Medicine, Seoul, Korea

Secondary achalasia due to submucosal invasion of esophageal squamous cell carcinoma (SCC) is a very rare condition. Here, we report a case of secondary achalasia diagnosed after distal esophagectomy, initially mistaken as primary achalasia. A 51-year-old man presented with progressive dysphagia for 2 months and mild weight loss. A barium swallow study, endoscopy, and manometry showed typical findings of primary achalasia. Pneumatic dilatation was performed, but esophageal perforation occurred as a complication. During surgical repair, no abnormalities around distal esophagus were found, and intraoperative esophageal biopsy revealed only inflammatory cells. During the following 8 months, the patient suffered from dysphagia caused by recurrent esophageal obstruction several times although of repeated balloon dilatation and esophageal stent insertion. Finally, he received a distal esophagectomy. The postoperative pathology revealed SCC at the distal esophagus and esophagogastric junction.

(J Neurogastroenterol Motil 2010;16:194-198)

Key Words

Achalasia, Squamous cell carcinoma, Balloon dilatation

\section{Introduction}

Achalasia is a rare swallowing disorder with an annual incidence of 1 in every $100,000 .{ }^{1}$ It is characterized by esophageal aperistalsis and abnormal lower esophageal sphincter relaxation in response to deglutition. The common form is primary or idiopathic achalasia, of which the cause remains unknown. Secondary forms of achalasia are less common, and various diseases including esophageal cancer cause it.
Progressive dysphagia to solids followed by liquids is the most characteristic symptom of primary achalasia. ${ }^{2}$ However, dysphagia in achalasia secondary to malignancy is relatively short in duration and usually develops when the malignant disease is far advanced. Therefore, a secondary form of achalasia caused by esophageal cancer can be easily diagnosed through upper gastrointestinal endoscopy. However, if esophageal cancer spreads into the submucosal layer, it is difficult to diagnose it until surgery.

Here, we report a case of secondary achalasia caused by submucosal invasion of esophageal cancer, initially mistaken as pri-

Received: March 15th, 2010 Accepted: April 6th, 2010

(c) This is an Open Access article distributed under the terms of the Creative Commons Attribution Non-Commercial License (http://creativecommons. org/licenses/by-nc/3.0) which permits unrestricted non-commercial use, distribution, and reproduction in any medium, provided the original work is properly cited.

*Correspondence: Jung Ho Park, MD

Department of Medicine, Sungkyunkwan University School of Medicine, Kangbuk Samsung Hospital, 108 Pyung-dong, Jongno-Gu, Seoul 110-102, Korea

Financial support: None.

Tel: +82-2-2001-2068, Fax: +82-2-2001-2485, E-mail: pjho3@hotmail.com

Conflicts of interest: None. 
mary achalasia.

\section{Case Report}

A 51-year-old man presented with a 2-month history of progressive dysphagia for solids and liquids and a $2 \mathrm{~kg}$ body weight loss. There was no prior history of gastroesophageal (GE) reflux, odynophagia, or other gastrointestinal symptoms. Social history was negative for tobacco use and alcohol intake. Physical examination was unremarkable and routine, and laboratory tests were within normal limits. A barium swallow study revealed a mildly dilated esophagus and a smoothly narrowed esophagogastric junction (Fig. 1).

Esophageal manometry showed absence of peristalsis and apparently incomplete relaxation of the lower esophageal sphincter, findings compatible with primary achalasia. A subsequent esophagogastroduodenoscopy showed no evidence of gross mucosal lesions, although a mild resistance to the passage of the endoscope through the GE junction to the cardia was noted. On retroflexed view, the esophagogastric junction appeared normal. Blind biopsy at the GE junction was performed several times, but revealed no pathologic abnormality.

A pneumatic dilation was performed using a $30 \mathrm{~mm}$ Rigiflex balloon dilator, which was inflated at 7 pound force per square inch for 1 minute (Fig. 2). After the procedure, the patient complained of severe pain over the epigastrium, and a high fever $\left(38.8^{\circ} \mathrm{C}\right)$ developed. A computed tomography $(\mathrm{CT})$ examination of the chest revealed pneumothorax and a small left pleural effusion. With the elevated white blood cell count and the continuous pain, the pleural effusion was interpreted as an infection, indicating that an operation was required. At left thoracotomy, about $150 \mathrm{~mL}$ of serosanguinous fluid and necrotic tissue debris was found in the pleural space. Intraoperative tissue biopsy revealed only chronic active inflammation with abscess formation and fibrinoid necrosis. The esophagus was sutured primarily, and following copious irrigation, the pleural space was drained with tubes. The patient recovered well and was discharged without any symptoms of dysphagia.

Four months later the patient's dysphagia recurred. Endoscopy revealed food retention and complete obstruction of the GE junction. However, a thoraco-abdominal CT scan and 4 biopsies from the mucosa of the GE junction did not reveal any abnormality. Because the patient refused surgical treatment, balloon dilatation was performed several times, but dysphagia recurred soon after. And then, a 12-cm-long self-expandable metal stent (TaeWoong Medical CO. LTD., Goyang, Korea) was inserted into the distal esophagus. Dysphagia resolved, but a proximal end of the stent was obstructed by ingrowing of normal esophageal mucosa. As a result of all these developments, the patient underwent surgical treatment.

Sleeve gastrectomy and distal esophagectomy with esophago-gastrostomy was performed, and on pathologic examination, squamous cell carcinoma (SCC) was discovered at the distal esophagus (Fig. 3). For staging of esophageal cancer, a positron emission tomography-computed tomography (PET-CT) scan was taken after surgery, and showed a large and hypermetabolic mass in the remaining distal esophagus, compatible with esophageal cancer. In addition, metastatic lymphadenopathy in the perisplenic area and metastatic lesions in the right lung were shown (Fig. 4). Palliative chemotherapy, including 5-fluorouracil and cisplatin, was performed. And until now, he got fifth cycle of chemotherapy and was well tolerated without complications related to the chemotherapy.

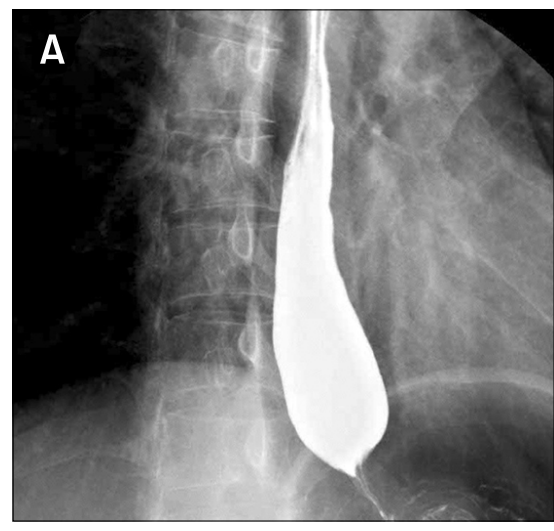

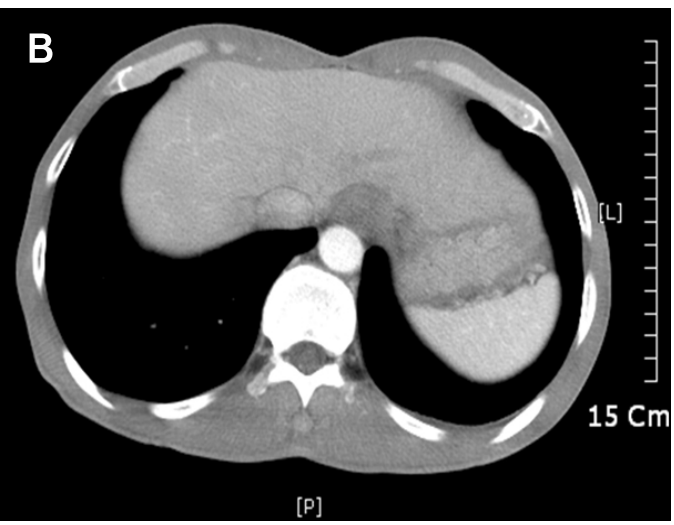

Figure 1. Barium esophagography and chest computed tomography (CT). (A) Barium esophagography demonstrates dilatation of distal esophagus and a bird' beak appearance. (B) Chest CT shows no abnormality around distal esophagus. 

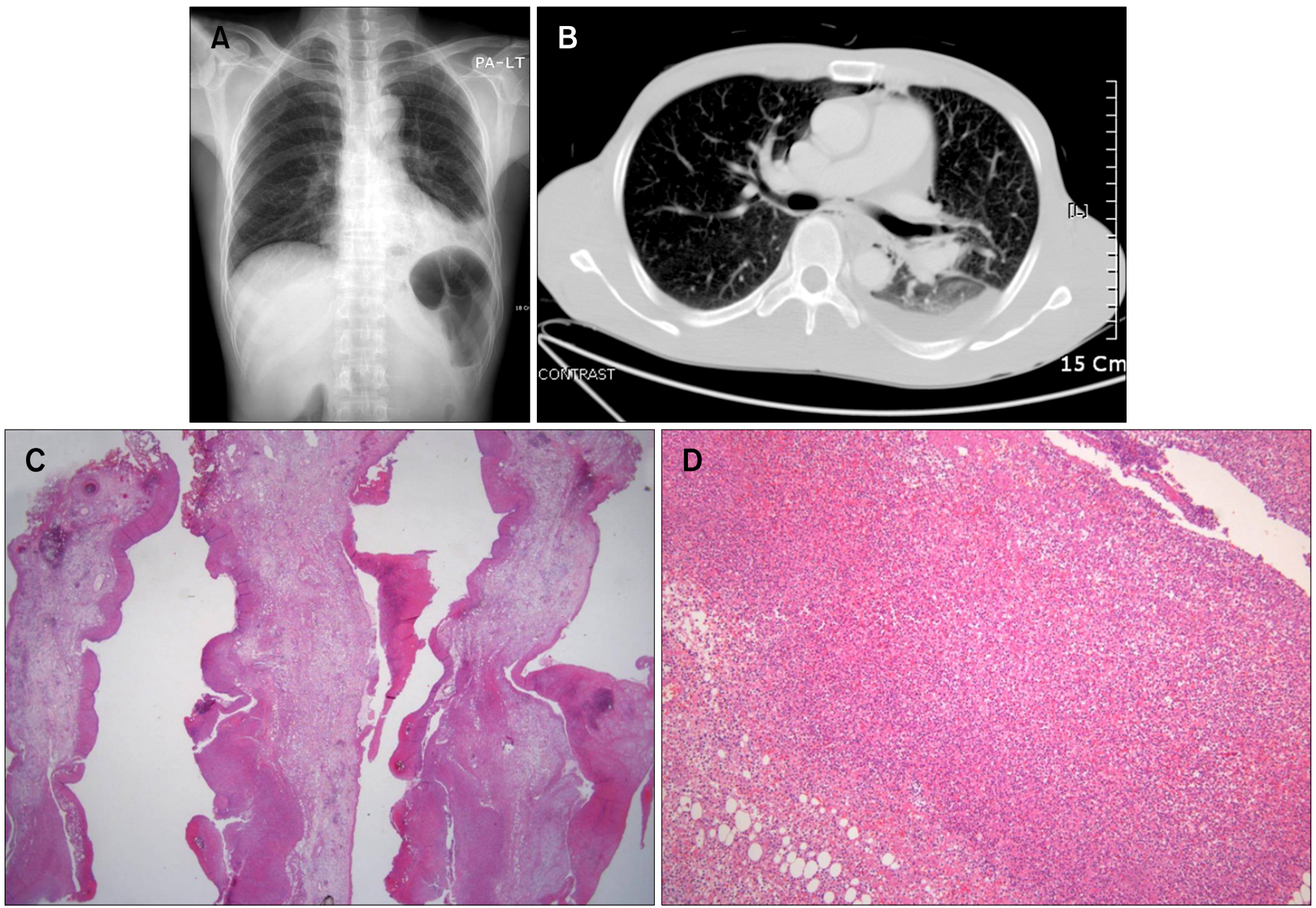

Figure 2. Esophageal rupture as a complication of pneumatic dilatation. (A) Chest X-ray and (B) chest computed tomography (CT) shows a left pleural effusion with the formation of a meniscus at the left costophrenic angle. (C) and (D) Chronic active inflammation with abscess formation and fibrinoid necrosis was noticed on the biopsy tissues $(\mathrm{C}: \mathrm{H} \& \mathrm{E}, \times 1.25, \mathrm{D}: \mathrm{H} \& \mathrm{E}, \times 100)$.
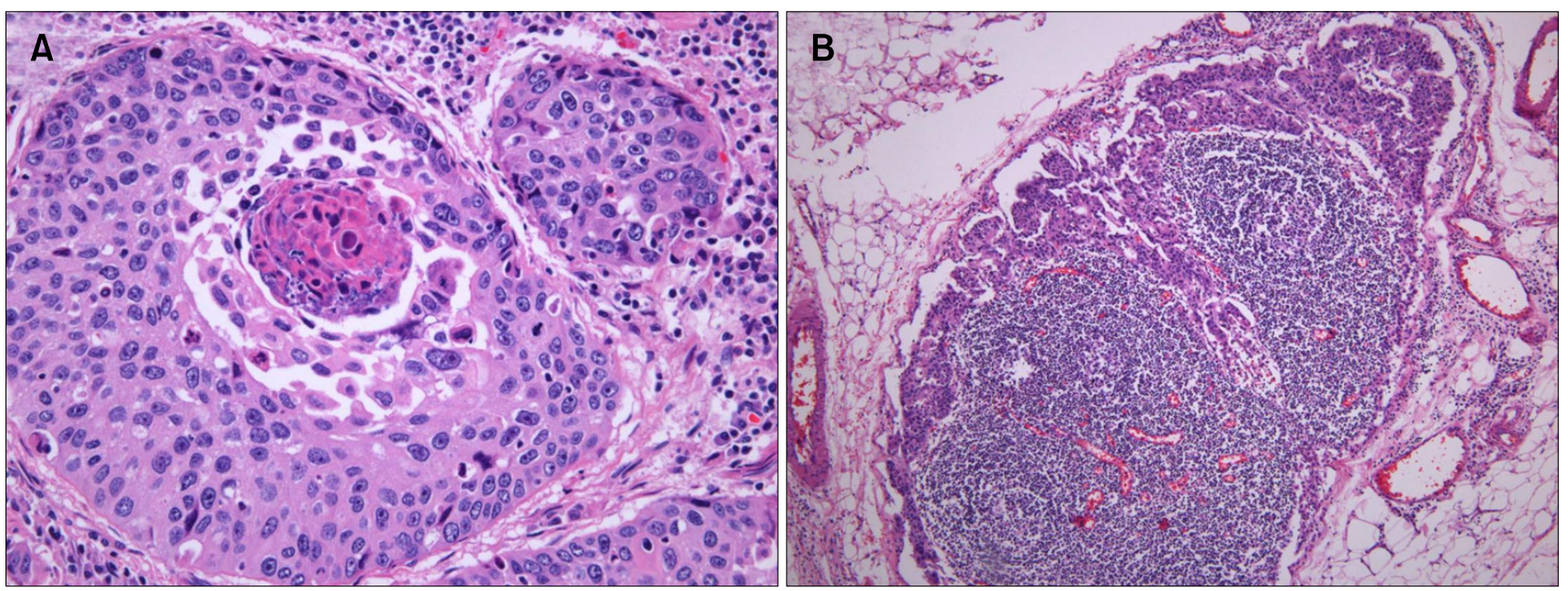

Figure 3. Esophageal squamous cell carcinoma from surgical specimen of distal esophagectomy. (A) Nests of atypical squamous cell with a keratin pearl formation were seen $(\mathrm{H} \& \mathrm{E}, \times 100)$. (B) Metastatic squamous cell carcinoma was seen in perigastric lymph node $(\times 50)$. 

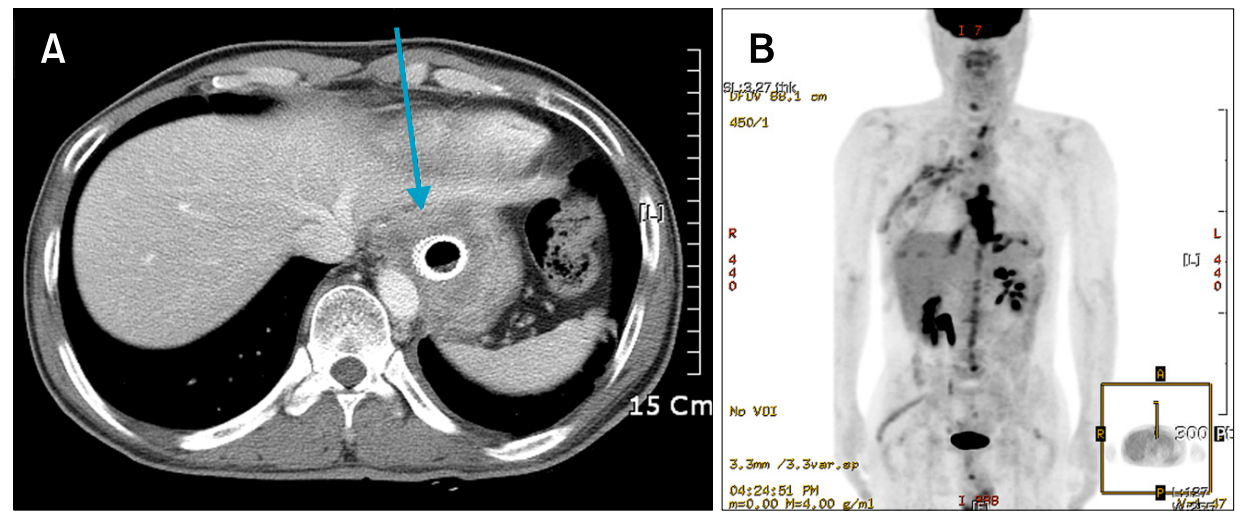

Figure 4. (A) Chest computed tomography (CT) revealed diffuse thickening of distal esophageal wall, which was mistaken as inflammatory reaction before distal esophagectomy, but was compatible with esophageal cancer (blue arrow: esophageal stent). (B) Markedly increased fluorodeoxyglucose (FDG) uptake was noticed in the remaining distal esophagus and perisplenic area.

\section{Discussion}

Secondary achalasia caused by malignant disease is an infrequent disorder. It accounts for 2-4\% of cases of achalasia, and has been reported with various types of malignancies. Nearly $75 \%$ of the patients with secondary achalasia are found to have underlying carcinoma of the cardia, but secondary achalasia may also be caused by SCC of the esophagus, ${ }^{5}$ or by other malignant tumors that metastasize to the mediastinum or the GE junction, including carcinoma of the lung, breast, pancreas, uterus, and prostate gland. $^{6-8}$

Several mechanisms have been postulated to explain the pathogenesis of secondary achalasia. First, the tumor might directly infiltrate the nerves within the myenteric plexus of the esophagus, causing physical disruption of the myenteric plexus by the tumor and deposition of eosinophilic cationic protein. ${ }^{9,10}$ Second, a paraneoplastic syndrome might affect the function of the distal esophagus. ${ }^{11}$ Third, esophageal obstruction might be caused by tumor infiltration or encasement of the GE junction. Secondary achalasia caused by gastric cardia cancer occurs after $50 \%$ or more circumferential invasion of the GE junction, ${ }^{12}$ and in the present case, histopathological study found a complete encasement of GE junction by SCC as well.

At first, after proper evaluation the patient's dysphagia seemed to be caused by esophageal achalasia. However, when esophageal perforation occurred after pneumatic dilatation, lymph node enlargement or wall thickening of the esophagus was not noticed on Chest CT, and tissue biopsy revealed chronic inflammatory tissues only. Thus it was impossible to conclude that the patient's symptoms were caused by malignancy. However, when obstruction of the GE junction recurred, esophageal cancer was seriously considered as a cause of secondary achalasia. The
CT scan was rechecked and multiple biopsies were taken from the GE junction; however, there was no evidence of malignant infiltration at the GE junction. We then proposed performing PET-CT for verification of a hidden malignancy, but patient did not agree to receive PET-CT. Eight months later, we found a 12-cm-long SCC arising around the GE junction. Considering there was no evidence of malignancy in earlier tissue biopsies or CT scan and the patient's symptom of dysphagia in the beginning, esophageal SCC might develop and progress submucosally, causing obstruction of GE junction. Even though such a case of SCC with submucosal progression is rare, there was a similar case report of a patient with SCC of the gastric cardia showing submucosal progression. ${ }^{13}$ In the case we report, no abnormal lesions were detected by endoscopic biopsy and diagnosis was made only after surgery.

Secondary achalasia induced by malignant tumors has different clinical features from primary achalasia. Secondary achalasia tends to occur at advanced age (more than 55 years), with short duration of symptoms (less than 6 months) and substantial weight loss at presentation [average weight loss 12 pounds (5.45 $\mathrm{kg})] .{ }^{4}$ If these criteria are met, patients are recommended to undergo additional imaging to rule out an occult malignancy. In our case, although the patient had short duration of symptoms (3 months), he was only 51 years old and weight loss was only $2 \mathrm{~kg}$ during 3 months. This could be another reason why it was very difficult to make a correct diagnosis in the beginning.

In conclusion, secondary achalasia caused by malignancy is very rare; however, if a patient with dysphagia has clinical features that suggest secondary achalasia or other unusual clinical outcomes such as restenosis, malignant diseases should be cautiously considered before the diagnosis of primary achalasia. A CT scan, endoscopic ultrasonography, and PET scan will help in the diagnosis of achalasia. 


\section{References}

1. Mayberry JF. Epidemiology and demographics of achalasia. Gastrointest Endosc Clin N Am 2001;11:235-248, v.

2. Vaezi MF, Richter JE. Current therapies for achalasia: comparison and efficacy. J Clin Gastroenterol 1998;27:21-35.

3. Sandler RS, Bozymski EM, Orlando RC. Failure of clinical criteria to distinguish between primary achalasia and achalasia secondary to tumor. Dig Dis Sci 1982;27:209-213.

4. Rozman RW Jr, Achkar E. Features distinguishing secondary achalasia from primary achalasia. Am J Gastroenterol 1990;85:13271330.

5. Rock LA, Latham PS, Hankins JR, Nasrallah SM. Achalasia associated with squamous cell carcinoma of the esophagus: a case report. Am J Gastroenterol 1985;80:526-528.

6. Feczko PJ, Halpert RD. Achalasia secondary to nongastrointestinal malignancies. Gastrointest Radiol 1985;10:273-276.
7. Joffe N. Right-angled narrowing of the distal oesophagus secondary to carcinoma of the tail of the pancreas. Clin Radiol 1979;30:33-37.

8. Eaves R, Lambert J, Rees J, King RW. Achalasia secondary to carcinoma of prostate. Dig Dis Sci 1983;28:278-284.

9. Kline MM. Successful treatment of vigorous achalasia associated with gastric lymphoma. Dig Dis Sci 1980;25:311-313.

10. Fredens K, Tottrup A, Kristensen IB, et al. Severe destruction of esophageal nerves in a patient with achalasia secondary to gastric cancer. A possible role of eosinophil neurotoxic proteins. Dig Dis Sci 1989;34:297-303

11. Liu W, Fackler W, Rice TW, Richter JE, Achkar E, Goldblum JR. The pathogenesis of pseudoachalasia: a clinicopathologic study of 13 cases of a rare entity. Am J Surg Pathol 2002;26:784-788.

12. Song CW, Chun HJ, Kim CD, Ryu HS, Hyun JH, Kahrilas PJ. Association of pseudoachalasia with advancing cancer of the gastric cardia. Gastrointest Endosc 1999;50:486-491.

13. Koide N, Hanazaki K, Kajikawa S, Adachi W, Hara E, Amano J. A squamous cell carcinoma of the gastric cardia showing submucosal progression. J Gastroenterol 2001;36:259-263. 